\title{
Introduction
}

\section{Jean-Philippe Touffut}

Few institutions have spread as widely throughout the world as central banks have. With 18 in existence at the end of the nineteenth century, their numbers had grown to 173 by the beginning of the twenty-first century. Although the first central banks were government banks, they progressively incorporated functions that made them into the bank of banks of the twentieth century. The role they were assigned changed during the 1990s as they were gradually required to become more independent from government control. The transformation has affected the whole planet: since 1990, the central banks of 34 countries have adopted new statutes.

As the instruments of monetary policy have changed, so its management has evolved: today more importance is attached to the transparency of the Bank's short- and mid-term objectives, rather than intermediate targets, such as exchange rate stability, growth of the monetary mass or the level of nominal interest rates. It is difficult to separate monetary policy from the instruments used to pursue it and the legitimacy with which it operates. In fact, the strictly economic arguments and the arguments to be drawn from historical analysis are indistinguishable. This work originates from the conference organized at the end of 2006 by the Cournot Centre, the aim of which was precisely to account for the institutional construction of central banks over the last few decades. Current events since the date of the conference have kept these institutions constantly at the centre of the economic stage: the leading role they are credited with playing in the economy has been the object of many commentaries outside this field, which do not always show a clear understanding of the foundations of their actions and the limits within which they operate.

Times have changed since Walter Bagehot wrote, in $1874,{ }^{1}$ 'in ordinary times the Bank is only one of many lenders, whereas in a panic it is the sole lender'. The role of the central bank has never been limited to lending. It overlooks economic activity, a position it owes to its discourse as much as to its actions. Thus, the central bank organizes its public statements in a very precise manner. The declarations of the governors, often widely reported in the press, represent a few lines in the vast mass of information, often very dense, that the central bank issues in the form of statistics or studies. One 
particularity of central bank publications is that they are the object of crossed interpretations that may conflict to the point of contradicting the initial expression of their authors. They are also the object of expectations, which can go against the intention of the communication.

Whatever the contradiction affecting the central bank's utterances, its formulation does not call into question the legitimacy expressed. The declaration of a central banker must be interpreted, like any utterance, according to its context. Classic expressions such as 'there is a risk that inflation will rise over the short term' or 'the markets are right to expect a forthcoming rise in the interest rate' ${ }^{2}$ share a particularity. They favour implicature over presupposition; 3,4 they express political sovereignty. With presupposition, responsibility for the implicit meaning of the message lies entirely with the speaker, whereas with implicature it lies entirely with the addressee. Central bankers do not adopt a discourse that is codified in its syntactical components, but one that depends on the context and is linked to the utterance; in other words, they can always take refuge behind the literalness of their statements.

The expression of the institution's independence reveals the mark of its autonomy in relation to its history. What the discourse of the central bank treats as given - all the arrangements that found its ahistoric universality is the product of a long collective path dependence that has led to this seemingly natural fact. ${ }^{5}$ The formulations of the central bank play a part in crediting economic agents with rational behaviour, sidestepping the question of the social conditions of access to this aptitude and the action required to render these conditions universal. The central bank is thus situated a priori in the sphere of market transactions. The countries that changed the statutes of their central banks during the 1990s had thus confirmed their conversion to this world of autonomous beliefs.

André Orléan explores the foundations, continuation and crises of this astonishing collective belief, in which the specific power of money is revealed. An explanation based on the legal enactment of the central bank's commitments proves to be unsatisfactory. Admittedly, the legal constraint does increase its credibility, given the heavy punishments incurred if it fails to honour its commitments, but, at best, it gives the central bank operational independence. Moreover, the legal constraints vary greatly from one country to another: in the United States, for example, the Federal Reserve Board has a triple mandate, whereas most of the other central banks have one main objective of price stability. A comparative analysis of the history of these institutions, corroborated by the study of two events described by André Orléan, shows that, fundamentally, money possesses its own power. This is, by definition, overlooked by the legalistic approach. The discrepancy between the constraints imposed by law and the historical 
grounding of the central bank is clearly exposed in the contribution by Carl Holtfrerich, devoted to the Reichsbank. From the establishment of the empire in 1871 to the introduction of the euro in 1999, the vicissitudes of the German central bank help to explain the foundations of the European Central Bank. The Reichsbank and then the Bundesbank were constantly subordinated to political objectives. Thus, Holtfrerich's analysis shows that the positions adopted by these institutions supported the promotion of a specific mercantilism, founded on exports. Restricting domestic demand, with the help of appropriate fiscal and monetary policies, makes it possible to keep imports and national inflation at a low level and to free productive resources in order to export more.

Benjamin Friedman's text raises the question of the relevance of central bankers' discourse on financial and non-financial economic activity. How should the policy objectives of a central bank be presented, internally, to the financial markets, or to the general public, as 'targets' of monetary policy? The questions of the transparency and accountability of the central bank bring into play all the representations of the institution in charge of public policy. Not only does monetary policy affect real economic results, such as production and employment, it is also, in practical terms, the only instrument available for pursuing public policy over the medium term. Policies must have objectives involving real results and dismiss the argument according to which monetary policy only has one independent instrument and should only concentrate on one sole economic aim.

If one judges the conformity of the central banks' discourses and recommendations to the results as presented by them over the last 15 years, 'monetary policy has been a great success', says Gerhard Illing in the introduction to his contribution. Their approach, inspired by the new neoclassical synthesis, would thus appear to be justified. This approach focuses on the commitment of central banks to exert an effective influence on long-term real interest rates through ensuring the credibility of its action on short-term interest rates and through communicating in advance information on the variations they envisage for future nominal interest rates. In this interpretation, the money supply only plays a marginal role. Part of the discourse is founded on the implementation of financial innovations, supposed to make the markets globally more efficient. These innovations may also generate problems of a more serious nature in the case of grave deterioration in the economic climate. During a period of crisis, the injection of liquidities by central banks can save the situation, but it can also amplify the problem: institutions that are already in debt, counting on intervention by the central banks in the event of a crisis, are encouraged to take even bigger risks. Upstream, the best policy consists in trying to prevent the formation of financial weaknesses, 
rather than undertaking to intervene, a costly commitment when facing the risk of financial collapse.

Problems of stability can conflict with the other objectives of the monetary authority. A central bank may hesitate to raise interest rates at the speed required for efficient stabilization of the economy. If there is a risk that a rate rise will endanger highly-indebted institutions, the central bank may find itself in an interest-rate trap: the problems of financial stability may oblige it to follow a trajectory of disproportionate gradualism. Along the same lines, during favourable periods, central banks may raise interest rates above the level required to deal with problems of stabilization, with the aim of giving themselves more room for manoeuvre when the climate worsens. Once again, the conditions of stability may be contradictory to an efficient policy of stabilization. The scenario developed in Illing's contribution is illustrated in the contemporary financial crisis that began in autumn 2007 and continues to unfold in summer 2008.

As Stephen Morris explained during the Cournot Centre conference, economists can no longer defend the idea of a dichotomy between the actions taken by the central bank, using the instruments at its disposal, and the play of economic agents, making their decisions independently. His contribution with Hyun Song Shin shows that it is in the grey area between the interpretations of both sides that decisions are shaped. Monetary policy endeavours to make up for failures in coordination: even if successful communication can reduce the weight of the direct instruments used by the central bank, such as the control of overnight interest rates, these instruments remain decisive during times of crisis. Morris and Shin point out that since the 1990s, central banks have had to master the art of coordinating expectations in the economy. When the policy of issuing information fails to coordinate expectations, the instruments are called to the rescue. Their impact can be as strong as their use is unforeseen. If the coordination of expectations is possible, then we have at our disposal a powerful and efficient instrument. This has been illustrated over the last 15 years by the successes achieved with greater transparency in communication by the central banks.

Transparency is the characteristic that most clearly differentiates today's central banks from those of the past. Over the last few years, this virtue has been extended to their objectives, procedures, principles, models and data. Is this a general trend? Is it likely to last? The chapter by Barry Eichengreen and Nazire Nergiz Dincer seeks to answer these questions. It shows that the trend is remarkably widespread. On the question of durability, it appears that the effects on the variability of inflation and production are positive. If the institutional systems that generate good results obtain public approval and support, there is every reason to believe that this trend towards transparency in monetary policy will endure. 
A number of studies have already been conducted on this subject, but we know little about the real trends of transparency, their correlates and consequences. Theoretical research has opened up some useful prospects, but its implications are limited, to say the least. Eichengreen and Dincer make a new contribution by creating an index of transparency for central banks. This index takes into account the different components and dimensions of transparency, and it covers a greater number of countries, over a longer period of time, than any previous study. Analysis of the spread of transparency over space and time brings recent trends to light. In which countries, and for what reasons have central banks become more transparent? What effect does transparency have on the persistence of inflation and on the variability of inflation and production? By considering both the determinants and the effects of transparency, the authors use the analysis of determinants to identify instrumental variables to illustrate the correlation observed between the different results.

The next two contributions, revised at the beginning of 2007, give a special flavour to this collection of papers, for they give the recipe for the financial crisis that was to strike the world eight months later. Like Nouriel Roubini, Takatoshi Ito describes the origins of a smouldering crisis, needing no more than a spark to set it ablaze, although the source of the spark was still unknown. Thus, Ito examines the role of central banks, faced with the global disequilibria in finance that have appeared since 2003. He finds four characteristics to be particularly disquieting: the very heavy current account deficit of the United States, the large current account surpluses of China, other East Asian and oil-producing countries, the accumulation of currency reserves by these countries because of their resistance to currency appreciation, and substantial entries of capital into the United States, together with low world interest rates. Chief among the elements that make it impossible for this phenomenon to continue is the durability of consumption in the United States, sustained by real estate growth. (The author's intuition proved right.) This is one of the ten scenarios that Roubini puts forward in order to understand the saga of the crisis developing before his eyes. Each version, from the most reassuring to the most devastating, reveals a conception of the central bank as either the focal point of anticipations of economic activity, or the keystone of the system. Until very recently, central bank action was limited to predicting systemic crises, that is, crises that endangered the economy's financial structure. Central banks thus acted as lenders of last resort in order to save the few institutions which made up the framework. In March 2008, the injection of 29 billion US dollars by the US Federal Reserve Board to help bail out Bear Stearns Companies, a brokerage firm, was unprecedented. For the moment, it is impossible to tell if this is the beginning of a shift in central banks' 
responsibility to non-banking institutions. Indeed, the Federal Reserve Board has not lent money to a non-banking institution since the 1930s. When a central bank acts in favour of a company that is not subject to the same strict regulatory and supervisory framework as banks are, it places non-banking institutions on an equal footing with banks, but without the same rules on regulatory capital, liquidity ratios, compliance and disclosure standards, to name just a few. Does this widen the legitimacy of central banks? What political body can justify this shift?

At the international level, the G8 has not become the directorate of international monetary affairs as it had hoped at one time. No political body has succeeded in dealing with the politico-economic discordance whose determinants have overtaken the eight most powerful countries in the world. The round table with Patrick Artus, Alan Blinder, Willem Buiter and Otmar Issing, chaired by Robert Solow, brings into perspective the concerns of central banks. What should their objectives be? What instruments will they be able to use? What are the consequences and effects of globalization on monetary policy? These questions take on different aspects, according to the monetary authorities' perception of communication and transparency, and depending on their independence and accountability. From one region of the world to another, the current crisis reminds us that the responses of the central banks redefine their influence on economic activity and their political position.

\section{NOTES}

1. Bagehot (1874).

2. Statement by the governor of the European Central Bank, 1 February 2006.

3. In linguistics, an 'implicature' is anything that is inferred from an utterance, but that is not a condition for the truth of the utterance.

4. Without going too deeply into the semantic analysis of the discourse, it appears that these two phrases do not stand up to the test of syntactical behaviour, negation or interrogation, which completely change the statement.

5. The central bank is thus presented as an institution of the economy, as described by Pierre Bourdieu (2000, pp. 15-17).

\section{REFERENCES}

Bagehot, Walter (1874), Lombard Street: A Description of the Money Market, New York: Scribner, Armstrong.

Bourdieu, Pierre (2000), Les structures sociales de l'économie, Paris: Seuil. 